\title{
Supramolecular tuning of energy transfer efficiency and direction in a bis(styryl) dye-crown ether conjugate
}

\author{
Daria V. Berdnikova ${ }^{\mathrm{a}, \mathrm{b}, *, 1}$, Yuri V. Fedorov ${ }^{\mathrm{a}}$, Olga A. Fedorova ${ }^{\mathrm{a}}$, Gediminas Jonusauskas ${ }^{\mathrm{c}}$ \\ ${ }^{a}$ A. N. Nesmeyanov Institute of Organoelement Compounds, Russian Academy of Sciences, Vavilova str. 28, 119991 Moscow, Russia \\ b RUDN University, Mikluho-Maklaya str. 6, 117198 Moscow, Russia \\ ${ }^{\mathrm{c}}$ Laboratoire Ondes et Matière d'Aquitaine - UMR CNRS 5798, Bordeaux University, Talence 33405, France
}

\section{A R T I C L E I N F O}

\section{Keywords:}

Bis(styryl) dye

Energy transfer

FRET

Crown ether

Cation complexation

Protonation

\begin{abstract}
A B S T R A C T
The control of the energy transfer (FRET) in a novel bischromophoric styryl(pyridinium) dye bearing two dif ferent crown ether residues is presented. Complexation of the dye with metal cations allows to tune the FRET efficiency without changing the transfer direction or to switch the FRET off, whereas protonation launches the FRET process in the opposite direction relative to the molecular structure.
\end{abstract}

\section{Introduction}

Photoinduced resonance energy transfer (FRET) is one of the basic processes in Nature that ensures photosynthetic conversion of the solar energy into chemical bonds in living organisms [1]. In artificial sys tems, photoinduced energy transfer is widely used in solar energy harvesting elements, ratiometric sensors, and organic photovoltaics [2 6]. Most of these applications require a stringent control of the FRET rate, efficiency and, especially, the direction. Along these lines, it is highly desirable that the direction of the energy transfer can be swit ched on demand. For example, such switching has been realized by changing the complexed metal cations in homo and heterodimers of metalloporphyrins [7], metallocyclodextrin assemblies [8] and [2] ca tenates incorporating the $\left[\mathrm{Ru}(\mathrm{tpy})_{2}\right]^{2+}$ fragment [9]. The control of the FRET direction can be also accomplished by protonation/deprotonation of the donor or acceptor unit as has been shown for oligophenylene vinylene (OPV) phenanthroline [10] and OPV fullerene [11] dyads and for multichromophoric BODIPY systems $[12,13]$. In addition, sev eral intriguing examples of switchable FRET directions have been re ported that use site specific solvent effects [14], temperature changes [15] or the electronic difference between cation binding sites [16,17]. Nevertheless, molecules or molecule assemblies that enable the fine regulation of the energy transfer processes based on supramolecular interactions are still rare and their discovery and development remains a topical challenge.

Herein, we present a dye crown ether conjugate whose energy transfer efficiency and direction is controlled by supramolecular com plexation and protonation. The system is based on a novel bischromo phoric styryl derivative 1 that is functionalized with benzo 15 crown 5 and azadithia 15 crown 5 ether units (Chart 1). Owing to the different affinity of the crown ether fragments towards metal ions or protons, the optical properties of each chromophore can be varied independently by introduction of appropriate metal cations or protonation, thus enabling the control of the energy transfer properties.

\section{Results and discussion}

\subsection{Synthesis of bis(styryl) dye 1}

The bis(styryl) dye 1 was obtained in $42 \%$ yield by condensation of the corresponding formylbenzocrown derivatives with $\gamma$ picoline and subsequent quaternization of the intermediate styryl(pyridine) species with 1,4 bis(bromomethyl)benzene (for details see ESI, Section 1). The parent monochromophoric dyes $\mathbf{2}$ and $\mathbf{3}$ were synthesized according to published protocols $[18,19]$.

\subsection{Steady state optical spectroscopy}

The absorption spectrum of bis(styryl) dye 1 exhibits two long wavelength absorption bands centered at 420 and $486 \mathrm{~nm}$ (Fig. 1, Table 1). Comparison with the absorption spectra of the related monochromophoric dyes $2\left(\lambda_{\text {abs }}=395 \mathrm{~nm}\right)[18]$ and $3\left(\lambda_{\text {abs }}=474 \mathrm{~nm}\right)$

\footnotetext{
* Corresponding author. A. N. Nesmeyanov Institute of Organoelement Compounds, Russian Academy of Sciences, Vavilova str. 28, 119991 Moscow, Russia

E-mail addresses: berdnikova@chemie-bio.uni-siegen.de, daria@ineos.ac.ru (D.V. Berdnikova).

${ }^{1}$ Present address: Universität Siegen, Organische Chemie II, Adolf-Reichwein-Str. 2, 57068 Siegen, Germany.
} 
<smiles></smiles><smiles>C[n+]1ccc(/C=C/c2ccc3c(c2)OCCOCCOCCOCCO3)cc1</smiles>

2

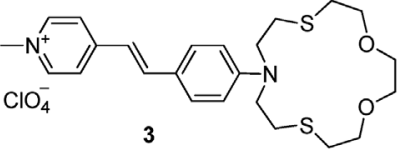

Chart 1. Chemical structures of styryl dyes 1-3.

[19] in acetonitrile, respectively (Figs. S3 and S4, ESI), allowed to as sign the band at $420 \mathrm{~nm}$ to the benzocrown substituted styryl chro mophore of dye 1 and the band at $486 \mathrm{~nm}$ to the azadithiacrown sub stituted one. For the sake of clarity, the benzocrown functionalized chromophore will be referred to as the $\mathrm{O}$ chromophore and the aza dithiacrown functionalized one as the $\mathrm{N}$ chromophore, to indicate that the respective electron donating heteroatom of the crown ether, that is directly conjugated with the styryl(pyridinium) fragment, determines the photophysical properties of the chromophore.

Complexation of the crown ether functionalities of dye $\mathbf{1}$ with metal cations leads to a blue shift of the corresponding absorption bands. It is known that oxacrown ethers have a high affinity to alkali and alkali earth metal ions [20], whereas the introduction of $\mathrm{N}$ or/and $\mathrm{S}$ atoms leads to higher affinity towards transition metal ions [21]. Based on this difference, the attachment of different crown ethers with diverse het eroatom substitution to the two chromophoric parts of 1 enables the independent regulation of the optical properties of each chromophore by complexation with appropriate cations. For the present study, we have selected $\mathrm{Mg}^{2+}$ and $\mathrm{Hg}^{2+}$ cations as they have the most effective interaction with the corresponding crown ethers [22,23]. The metal cations were used as perchlorate salts. To avoid introduction of dif ferent anions that may potentially influence complexation, we used perchloric acid for protonation of the azadithiacrown ether residue.

Addition of $\mathrm{Mg}\left(\mathrm{ClO}_{4}\right)_{2}$ to a solution of $\mathbf{1}$ results in a blue shift $(\Delta \lambda=52 \mathrm{~nm})$ of the $\mathrm{O}$ chromophore absorption whereas the $\mathrm{N}$ chro mophore absorption remains unaffected (Fig. 1A, Table 1). Conversely, the introduction of $\mathrm{Hg}\left(\mathrm{ClO}_{4}\right)_{2}$ and $\mathrm{HClO}_{4}$ causes a blue shift of the $\mathrm{N}$ chromophore absorption $\left(\mathrm{Hg}\left(\mathrm{ClO}_{4}\right)_{2}: \Delta \lambda=124 \mathrm{~nm} ; \quad \mathrm{HClO}_{4}\right.$ : $\Delta \lambda=148 \mathrm{~nm}$ ) without significant changes of the $\mathrm{O}$ chromophore $\mathrm{ab}$ sorption (Fig. 1B and C, Table 1). The stability constants of the com plexes of 1 were obtained from the spectrophotometric titration data (Figs. S1 and S2, ESI) and are collected in Table 1.

According to the classical description of the Förster resonance en ergy transfer (FRET), an efficient energy transfer requires a spectral overlap between the emission of the donor and the absorption of the acceptor chromophores [24,25]. To estimate the potential for an
Table 1

Optical properties and stability constants of $\mathbf{1}$ and its complexes in acetonitrile.

\begin{tabular}{llll} 
Compound & $\lambda_{\text {abs }}, \mathrm{nm}$ & $\begin{array}{l}\varepsilon \times 10^{4}, \\
\mathrm{~L} \mathrm{~mol}{ }^{1} \mathrm{~cm}^{1}\end{array}$ & $\log K$ \\
\hline $\mathbf{1}$ & 420,486 & $3.27,3.63$ & - \\
$\mathbf{1}-\mathrm{Mg}^{2+}$ & 368,486 & $3.12,3.71$ & $3.27 \pm 0.03$ \\
$\mathbf{1}-\mathrm{Hg}^{2+}$ & 373,393 & $3.37,3.43$ & $>7^{\mathrm{a}}$ \\
$\mathbf{1}-\mathrm{H}^{+}$ & 404,338 & $3.96,3.07$ & $3.38 \pm 0.01$
\end{tabular}

${ }^{\text {a }}$ The value is too high to be determined from spectrophotometric titration.

intramolecular energy transfer in dye $\mathbf{1}$ and its complexes, the optical characteristics of each chromophore were assessed separately with parent monochromophoric dyes $\mathbf{2}$ and $\mathbf{3}$ and their complexes with $\mathrm{Mg}^{2+}, \mathrm{Hg}^{2+}$ and $\mathrm{H}^{+}$. The fluorescence of 2 overlaps significantly with the absorption of 3 (Fig. 2A). Therefore, within the bischromophoric dye 1 , the $\mathrm{O}$ chromophore may act as an energy donor (ED), whereas the $\mathrm{N}$ chromophore is an energy acceptor (EA). The blue shift of the fluorescence of 2 upon complexation with $\mathrm{Mg}^{2+}$ provides more pro nounced spectral overlap between the fluorescence of the $\mathrm{O}$ chromo phore (ED) and the absorption of the $\mathrm{N}$ chromophore (EA) (Fig. 2B), thus favoring energy transfer in complex $1 \mathrm{Mg}^{2+}$. At the same time, the absorption and fluorescence spectra of dye 2 and complex $3 \mathrm{Hg}^{2+}$ do not overlap so that an energy transfer is not feasible in the complex of dye 1 with $\mathrm{Hg}^{2+}$ (Fig. S5, ESI). Protonation of dye 3 results in a suf ficient spectral overlap of the fluorescence of $3 \mathrm{H}^{+}$and the absorption of 2 which leads to a reversal of the donor and acceptor functions of the chromophores in the energy transfer process (Fig. 2C). Thus, in the bischromophoric system $1 \mathrm{H}^{+}$the protonated $\mathrm{N}$ chromophore acts as energy donor and the $\mathrm{O}$ chromophore as energy acceptor.

\subsection{Theoretical calculation of the energy transfer efficiency}

To estimate the efficiency of the energy transfer in $\mathbf{1}$ and its com plexes $1 \mathrm{Mg}^{2+}$ and $1 \mathrm{H}^{+}$, we performed calculations according to Förster resonance theory (for details seeESI, Section 5) [25]. Taking into account the crucial influence of the interchromophoric distance on FRET efficiency, on one side, and high conformational lability of $\mathbf{1}$, on the other side, we considered two extreme conformations of dye 1 with maximally close and maximally remote mutual positions of the chro mophores (Fig. S11, ESI). After geometry optimization (MOPAC 2016, PM7), the corresponding interchromophoric distances were determined as $r_{\text {max }}=15 \AA$ and $r_{\text {min }}=9 \AA$. Based on these values, we obtained the following theoretical intervals of the FRET efficiencies $\Phi_{\text {FRET }}$ (th): 97.4 $99.9 \%$ for $\mathbf{1}, 93.799 .7 \%$ for $1 \mathrm{Mg}^{2+}$ and $42.894 .1 \%$ for $1 \mathrm{H}^{+}$. Therefore, the expected FRET efficiencies in the studied species in most cases are very high. At the same time, the pronounced difference in the theoretical values $\Phi_{\text {FRET }}($ th) for two extreme conformations of complex $1 \mathrm{H}^{+}$arises from the relatively small value of the Förster radius $R_{0}=14 \AA$, i.e. the distance at which the energy transfer efficiency is
A

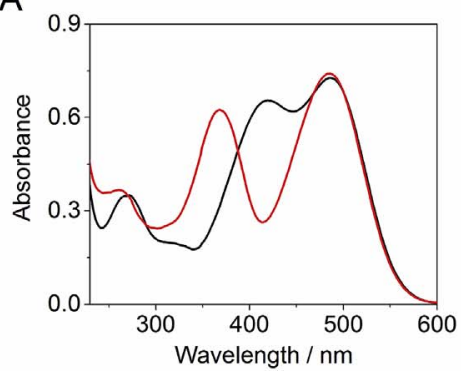

B

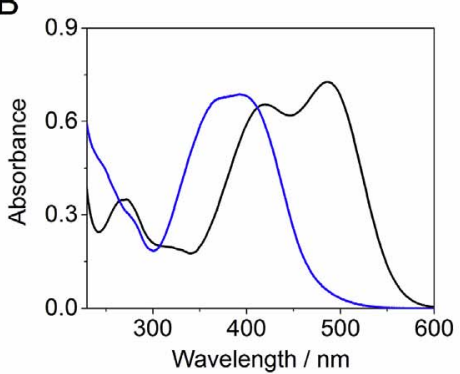

C

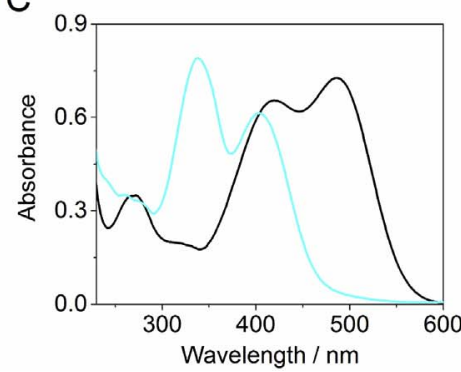

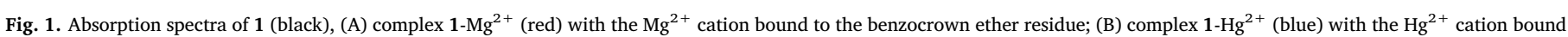

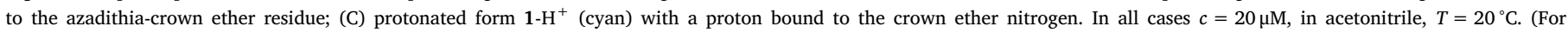
interpretation of the references to colour in this figure legend, the reader is referred to the Web version of this article.) 


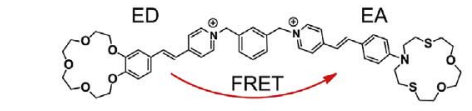

A

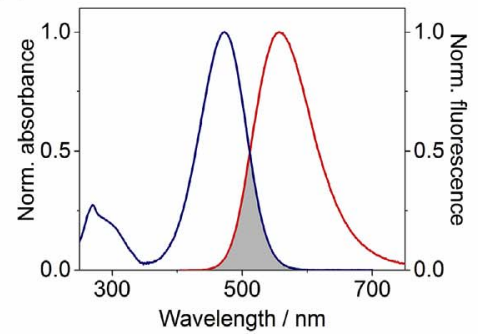

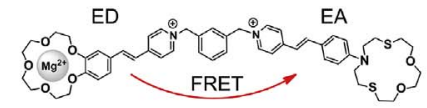

B

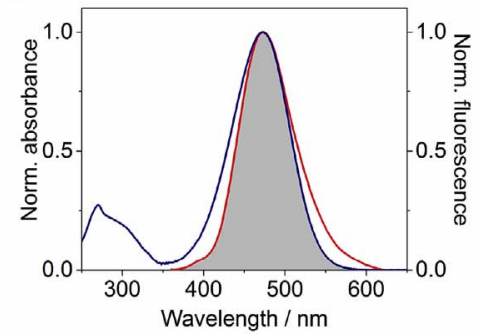

C
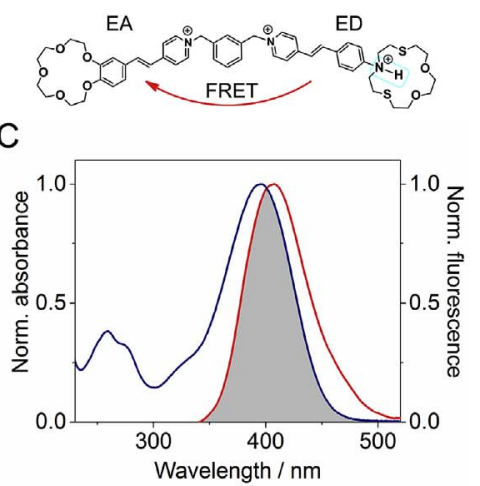

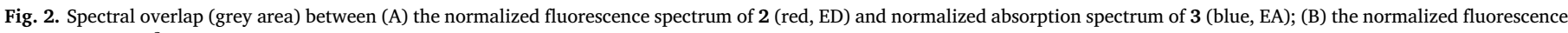

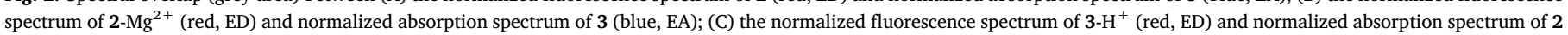
(blue, EA) in acetonitrile. (For interpretation of the references to colour in this figure legend, the reader is referred to the Web version of this article.)

$50 \%$ [25], for this complex in comparison to 1 and complex $1 \mathrm{Mg}^{2+}$ (Table S1, ESI). For $1 \mathrm{H}^{+}, r_{\max }=15 \AA$ that is larger than $R_{0}$ which leads to the drastic decrease of the estimated FRET efficiency for the corre sponding conformation.

\subsection{Time resolved fluorescence spectroscopy}

The emission properties of 1 and its complexes $1 \mathrm{Mg}^{2+}$ and $1 \mathrm{H}^{+}$ were studied by steady state and time resolved fluorescence spectro scopy. Upon excitation of dye $\mathbf{1}$ in the $\mathrm{O}$ chromophore absorption band, emission of both chromophores was detected in the steady state and time resolved fluorescence spectra (Fig. 3A; Fig. S6, ESI). This result indicates that for a part of the excited molecules, energy transfer from the $\mathrm{O}$ chromophore to the $\mathrm{N}$ chromophore does not occur.

Since two different excited states are formed upon photoexcitation of dye 1, its relaxation should follow two main pathways. Thus, for a part of the molecules the excited state relaxation occurs through emission of the $\mathrm{N}$ chromophore that is either excited directly or in directly by energy transfer from the excited O chromophore. For the remaining molecules with the excited $\mathrm{O}$ chromophore, energy transfer does not occur and the system relaxes according to the deactivating pathways of the $\mathrm{O}$ chromophore. The resulting fluorescence lifetimes support this assumption (Fig. 4A). The fast component of the decay kinetics belongs to the relaxation of the $\mathrm{N}$ chromophore through the formation of TICT states due to the rotation around the single bond in the $\mathrm{CH} \mathrm{PhN}$ fragment [26], as supported by close $\tau_{1}$ values for dye $\mathbf{1}$ and parent monochromophoric dye $\mathbf{3}$ (Table 2). The slow component of the kinetics represents an averaged value of both decay times of the $\mathrm{O}$ chromophore as compared with the $\tau$ values of the parent mono chromophoric dye $\mathbf{2}$ (Table 2).

Due to the significant blue shift of the $\mathrm{Mg}^{2+}$ bound $\mathrm{O}$ chromophore absorption (ED), the donor can be excited selectively at $350 \mathrm{~nm}$ because the $\mathrm{N}$ chromophore (EA) has almost no absorption at this wavelength (Fig. S4, ESI). As can be seen from the steady state and time resolved fluorescence spectra (Fig. 3B; Fig. S7, ESI), the excitation of the com plex $1 \mathrm{Mg}^{2+}$ at $350 \mathrm{~nm}$ leads only to one fluorescence band centered at
$620 \mathrm{~nm}$ that corresponds to the emission of the $\mathrm{N}$ chromophore (EA), which indicates the occurrence of an efficient energy transfer from the $\mathrm{Mg}^{2+}$ complexed $\mathrm{O}$ chromophore (ED) to the $\mathrm{N}$ chromophore (EA). Accordingly, the fast component of the decay kinetics of $1 \mathrm{Mg}^{2+}$ is assigned to the emission of the $\mathrm{N}$ chromophore (EA) through TICT states as in the parent dye 3 (Fig. 4B, Table 2). The residual long lived second component belongs to the trace amount of non complexed $\mathrm{O}$ chromophore due to relatively low stability constant of complex $\mathbf{1}$ $\mathrm{Mg}^{2+}$.

In the case of protonated dye $1 \mathrm{H}^{+}$the donor and acceptor functions of the chromophores are reversed in the energy transfer process, namely, the protonated $\mathrm{N}$ chromophore acts as $\mathrm{ED}$ and the $\mathrm{O}$ chromo phore becomes EA. Accordingly, excitation of complex $1 \mathrm{H}^{+}$at $350 \mathrm{~nm}$ results in only one fluorescence band in the region of $560 \mathrm{~nm}$ that be longs to the emission of O chromophore (EA) (Fig. 3C; Fig. S8, ESI). The fluorescence decay curve of $1-\mathrm{H}^{+}$is biexponential (Fig. 4C) which is typical for the relaxation of the $\mathrm{O}$ chromophore ( $c f . \tau$ values for com pound 2, Table 2). The fast component is assigned to the relaxation through TICT states, whereas the slow component corresponds to the $E$ $Z$ isomerization [27].

To obtain the experimental values of the FRET efficiencies, the rate of the energy transfer process in $\mathbf{1}$ and its complexes $\mathbf{1} \mathrm{Mg}^{2+}$ and $\mathbf{1} \mathrm{H}^{+}$ was determined with ultrafast transient absorption spectroscopy (TRABS). Representative results from TRABS experiments in the case of energy transfer towards the $\mathrm{N}$ chromophore (free 1 , complex $1 \mathrm{Mg}^{2+}$ ) are displayed in Fig. 5A taking $\mathbf{1} \mathrm{Mg}^{2+}$ as example. There are three main processes occurring after the pump pulse: i) absorption of the dimethylaniline cation radical at about $450 \mathrm{~nm}$ [28], ii) ground state bleaching of the $\mathrm{N}$ chromophore at the region of $500 \mathrm{~nm}$, and iii) sti mulated emission of the $\mathrm{N}$ chromophore at about $620 \mathrm{~nm}$ (Fig. 5A; Fig. S9, ESI). The time dependent red shift of the stimulated emission maximum arises from the dynamic solvent relaxation that reflects the rearrangement of the solvent molecules around the excited chromo phore, whose polarity changes in comparison to the ground state due to the photoinduced intramolecular charge transfer (ICT). In the case of energy transfer towards the $\mathrm{O}$ chromophore (protonated dye $1 \mathrm{H}^{+}$),
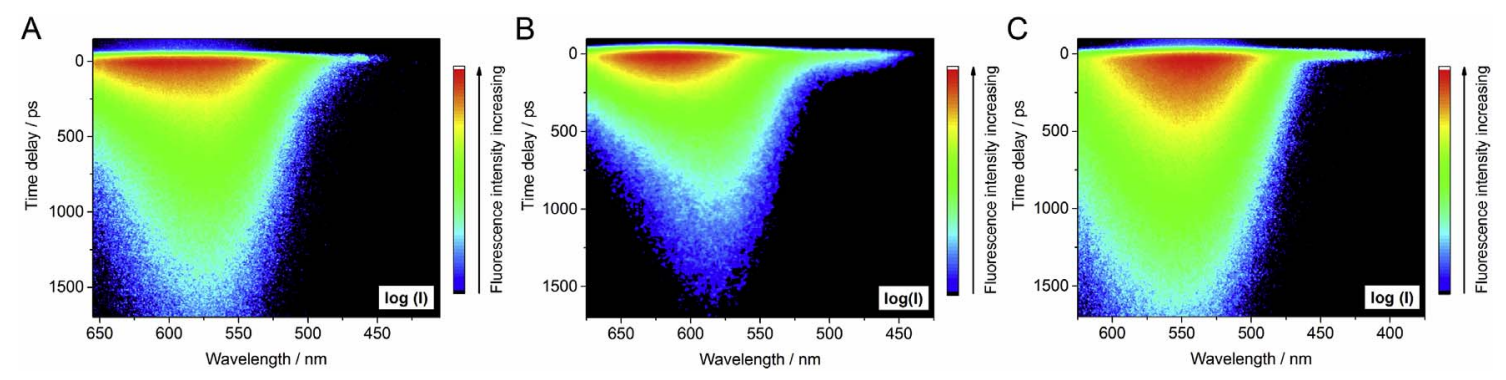

Fig. 3. Time-resolved fluorescence maps of (A) $1, \lambda_{\mathrm{ex}}=400 \mathrm{~nm}$, (B) $1-\mathrm{Mg}^{2+}, \lambda_{\mathrm{ex}}=350 \mathrm{~nm}$, and (C) $1-\mathrm{H}^{+}, \lambda_{\mathrm{ex}}=350 \mathrm{~nm}$, in acetonitrile. 
A

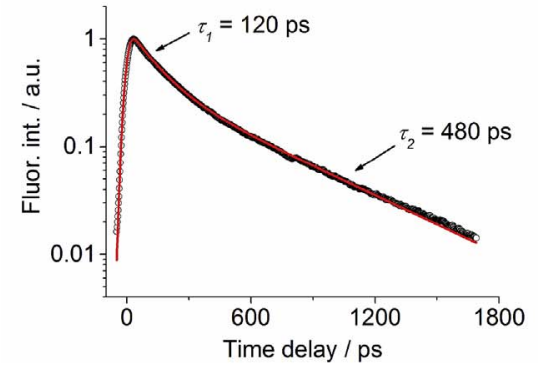

B

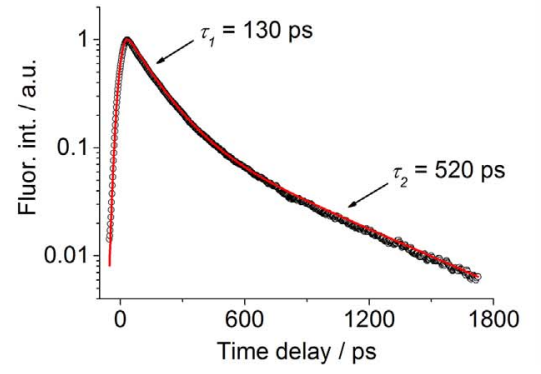

C

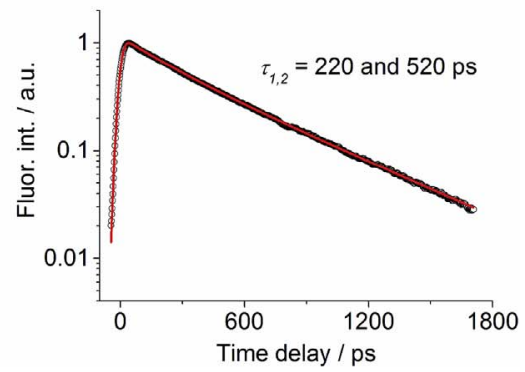

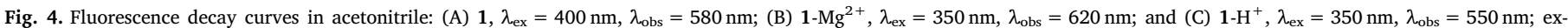
perimental data: empty circles, fitting curve: red line. (For interpretation of the references to colour in this figure legend, the reader is referred to the Web version of this article.)

Table 2

Fluorescence lifetimes $\tau$, energy transfer time constants $\tau_{\text {FRET }}$, theoretical $\Phi_{\text {FRET }}($ th) and experimental $\Phi_{F R E T}$ (exp) energy transfer efficiencies for dye $\mathbf{1}$, its complexes $\mathbf{1}-\mathrm{Mg}^{2+}$ and $1-\mathrm{H}^{+}$in acetonitrile. Fluorescence lifetimes $\tau$ for dyes $\mathbf{2}$ and $\mathbf{3}$ in acetonitrile.

\begin{tabular}{lllll}
\hline Compound & $\tau, \mathrm{ps}$ & $\tau_{\text {FRET }}, \mathrm{ps}$ & $\Phi_{\text {FRET }}(\mathrm{th}), \%$ & $\Phi_{\text {FRET }}(\mathrm{exp}), \%$ \\
\hline $\mathbf{1}$ & 120,480 & 0.150 & $97.4-99.9$ & 100.0 \\
$\mathbf{1}-\mathrm{Mg}^{2+}$ & 130,520 & 0.150 & $93.7-99.7$ & 99.8 \\
$\mathbf{1}-\mathrm{H}^{+}$ & 220,520 & 0.220 & $42.8-94.1$ & 95.6 \\
$\mathbf{2}$ & $310,650^{\mathrm{a}}$ & - & - & - \\
$\mathbf{3}$ & $100,230^{\mathrm{b}}$ & - & - & - \\
\hline
\end{tabular}

${ }^{\text {a }}$ Data from Ref. [27].

b Data from Ref. [19].

two processes are observed on a TRABS map, namely: i) absorption of the isomeric dimethoxybenzene cation radicals at $450 \mathrm{~nm}$ [29] and ii) stimulated emission of the $\mathrm{O}$ chromophore at the region of $550 \mathrm{~nm}$ (Fig. 5B).

Analysis of the TRABS data allowed to determine the energy transfer time constants $\tau_{\text {FRET }}$ (Table 2; Fig. S10, ESI). For free dye 1 and its complex $1 \mathrm{Mg}^{2+}, \tau_{\text {FRET }}$ data were obtained from the ground state bleaching kinetics of the energy acceptor ( $\mathrm{N}$ chromophore) at $500 \mathrm{~nm}$ and $505 \mathrm{~nm}$, respectively (Figs. S10A and S10B, ESI). For the proto nated form $1 \mathrm{H}^{+}$, $\tau_{\mathrm{FRET}}$ was determined from the kinetics of develop ment of the stimulated emission band of the energy acceptor ( $\mathrm{O}$ chro mophore) at $525 \mathrm{~nm}$ (Fig. S10C, ESI). Experimental energy transfer efficiencies $\Phi_{\text {FRET }}(\exp )$ were calculated from the $\tau_{\text {FRET }}$ values according to Equation (1).

$\Phi_{\mathrm{FRET}}=\left(1-\tau_{\mathrm{FRET}} / \tau_{0}\right) \cdot 100 \%$

In equation ( 1 ), $\tau_{\mathrm{FRET}}$ is energy transfer time constant obtained from the TRABS experiment, $\tau_{0}$ is excited state lifetime of the energy donor in the absence of the energy acceptor.

In free dye 1 , the energy donor is the $\mathrm{O}$ chromophore, whose excited state lifetime of $\tau_{0}=650 \mathrm{ps}$ was determined from the fluorescence decay kinetics of dye $\mathbf{2}$ that contains the isolated O chromophore [27].

A

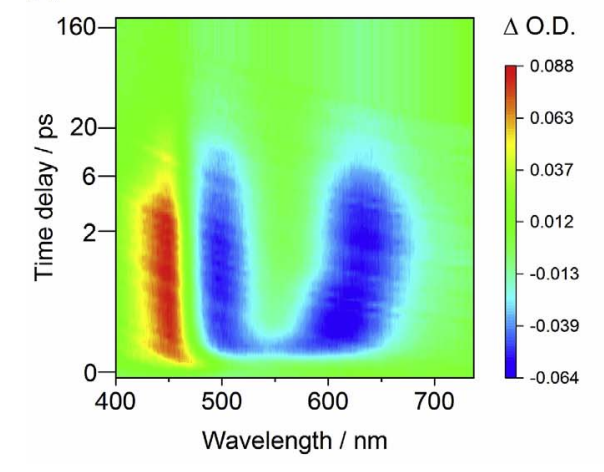

In the case of complex $1 \mathrm{Mg}^{2+}$, we considered the reported lifetime of $\tau_{0}=70 \mathrm{ps}$ of the magnesium complex of dye 2 [27]. For the protonated form $1 \mathrm{H}^{+}$, in which the energy donor is the protonated $\mathrm{N}$ chromo phore, the lifetime of $\tau_{0} \sim 5$ ps was estimated tentatively from the fluorescence decay kinetics of the protonated dye $3 \mathrm{H}^{+}$that contains the isolated $\mathrm{N}$ chromophore [19]. As can be seen from Table 2, the experimental FRET efficiencies $\Phi_{\text {FRET }}(\exp )$ in the studied systems are very high and in the case of free dye 1 and the complex $1 \mathrm{Mg}^{2+}$ exceed $99 \%$.

Based on the previous discussion, the reasons for the incomplete energy transfer in dye 1 still need to be explained. As was shown, the evaluation of both theoretical and experimental data revealed a $>99 \%$ FRET efficiency for 1 . At the same time, clear presence of the fluores cence of energy donor ( $\mathrm{O}$ chromophore) at the region of $560 \mathrm{~nm}$ (Fig. 3A; Fig. S6, ESI) indicates that some of the excited molecules of 1 are not involved in the FRET process. Since the relative orientation of the dipole transition moments of the ED and the EA significantly in fluences the efficiency of the FRET [24], we assume that energy transfer in $\mathbf{1}$ cannot be realized partially for geometrical reasons. In theoretical calculations, we considered the random orientation of the chromo phores in $\mathbf{1}$ due to the high conformational flexibility of the xylylene spacer (for details see ESI, Section 6). This flexibility, however, is true only for the isolated molecules of $\mathbf{1}$ in solution. At the same time, it is known that charged styryl dyes readily undergo dipole dipole ag gregation due to the highly polar character of the chromophores [30]. Considering the significantly restricted freedom of movement of the aggregated molecules, it is tempting to assume that the aggregation locks some dye molecules in a geometry that is unfavorable for energy transfer.

To provide evidence for the aggregation, we analyzed the absorp tion spectra of dye $\mathbf{1}$ and an equimolar mixture of the parent dyes $\mathbf{2}$ and 3 (Fig. 6). Hence, deconvolution of the spectrum of the monomeric dyes mixture with Gaussian shaped absorption bands gave two components at about 21000 and $25000 \mathrm{~cm}^{-1}$ corresponding to the absorption spectra of the individual chromophores (Fig. 6A). Deconvolution of the
Fig. 5. Time-resolved TRABS maps for (A) $1-\mathrm{Mg}^{2+}$ and (B) $1-\mathrm{H}^{+}, \lambda_{\mathrm{ex}}=345 \mathrm{~nm}$, acetonitrile.

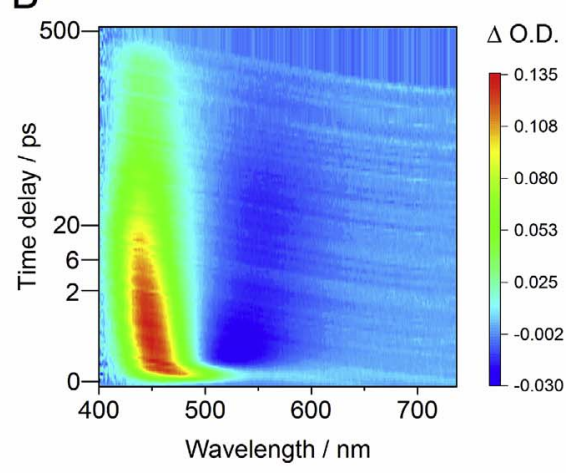


A

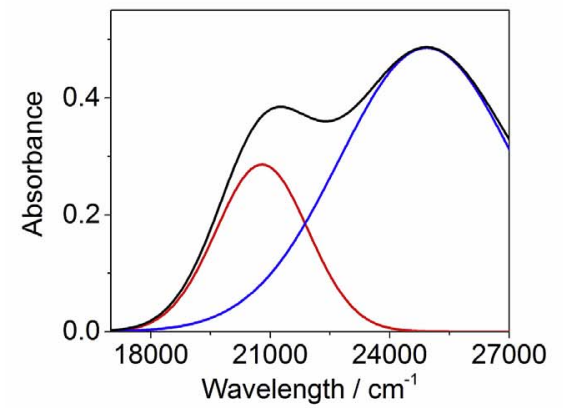

B

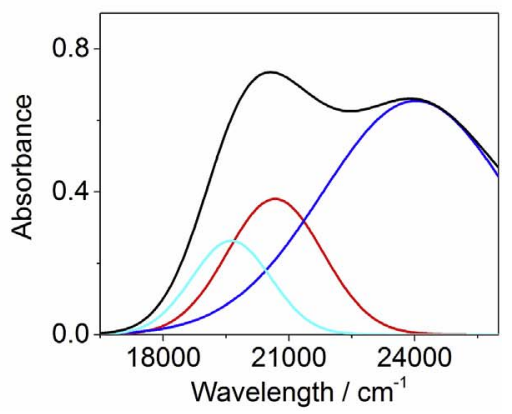

Fig. 6. (A) Absorption spectrum of the equimolar mixture of monomeric dyes 2 and 3 (black, for each dye $c=20 \mu \mathrm{M}$ ) and its deconvolution: blue line corresponds to the O-chromophore, red line corresponds to the $\mathrm{N}$-chromophore. (B) Absorption spectrum of bischromophoric dye 1 (black, $c=20 \mu \mathrm{M}$ ) and its deconvolution: blue line corresponds to the O-chromophore, red line corresponds to the $\mathrm{N}$-chromophore, and cyan line represents the absorption of the aggregates. (For interpretation of the references to colour in this figure legend, the reader is referred to the Web version of this article.) spectrum of bischromophoric dye $\mathbf{1}$ showed the presence of the same bands as in the case of the monomeric dyes mixture and additionally revealed the third component at about $19500 \mathrm{~cm}^{-1}$ (Fig. 6B). This new band is shifted to the lower energy region that is indicative of the formation of J type aggregates [31]. The detailed investigation of the aggregation pattern, however, falls beyond the scope of the present manuscript.

As a result, the spectral analysis supports the aggregation of $\mathbf{1}$ that is proposed to be a likely reason for incomplete energy transfer due to geometrical reasons. At the same time, for non aggregated molecules of 1 the efficiency of FRET is close to $100 \%$ as indicated by experimentally obtained energy transfer efficiencies $\Phi_{\text {FRET }}$ (exp) and additionally supported by the theoretical calculations (Table 2). Unlike dye $\mathbf{1}$, the complexes $\mathbf{1} \mathrm{Mg}^{2+}$ and $\mathbf{1} \mathrm{H}^{+}$show no fluorescence of the ED (Fig. 3B and $\mathrm{C}$ ) which is in agreement with both theoretical and experimental $\Phi_{\text {FRET }}$ values (Table 2). We explain this observation by dissociation of the aggregates upon complexation due to the decrease of the dipole moments of complexed chromophores and the increase of the overall positive charge of the molecules resulting in the electrostatic repulsion between aggregated molecules.

\section{Conclusions}

To sum up, we have designed and synthesized the novel bis(styryl) dye 1 bearing benzo 15 crown 5 and azadithia 15 crown 5 functional ities. In the free state, dye 1 undergoes efficient intramolecular energy transfer whereas upon aggregation of 1 the FRET process is partially blocked. Complexation of $\mathrm{Mg}^{2+}, \mathrm{Hg}^{2+}$ cations and protonation allow independent manipulation of the optical properties of each chromo phore within a single dye molecule, thus enabling the regulation of the FRET parameters in $\mathbf{1}$ by supramolecular complexation. Interestingly, binding of 1 with $\mathrm{Hg}^{2+}$ cations results in drastic decrease of the FRET efficiency, whereas interaction with $\mathrm{Mg}^{2+}$ and $\mathrm{H}^{+}$has just slight in fluence on this parameter. Notably, complexation with $\mathrm{Mg}^{2+}$ does not change the energy transfer direction in comparison to free dye $\mathbf{1}$, whereas protonation results in the reversion of the direction of FRET relative to the molecular structure.

\section{Experimental section}

All reagents and solvents were obtained from commercial sources and used as received. ${ }^{1} \mathrm{H}$ NMR spectra were recorded at 300 or $600 \mathrm{MHz},{ }^{13} \mathrm{C}$ NMR spectra were recorded at $150 \mathrm{MHz}$ at ambient temperature using $5 \mathrm{~mm}$ tubes. Chemical shifts were determined with accuracy of $0.01 \mathrm{ppm}$ and $0.1 \mathrm{ppm}$ for ${ }^{1} \mathrm{H}$ and ${ }^{13} \mathrm{C}$ spectra, respectively, and are given relative to the residual signal of the solvent that was used as internal reference. Spin spin coupling constants for the proton spectra were determined with accuracy of $0.2 \mathrm{~Hz}$. The proton NMR signal assignments were performed using COSY and NOESY 2D NMR techniques. The carbon NMR signal assignments were performed by means of HSQC and HMBC 2D NMR techniques. Electrospray ionization
(ESI) mass spectra were detected in the mode of full mass scanning of positive ions on a tandem dynamic mass spectrometer equipped with a mass analyzer with an octapole ionic trap. High resolution mass spectra were recorded on a time of flight instrument in a positive ion mode using electrospray ionization method. Elemental analysis was per formed at the Laboratory of Microanalysis of A. N. Nesmeyanov Institute of Organoelement Compounds of RAS, Moscow, Russia. Electronic absorption spectra were measured on Varian Cary 100 spectrophotometer. Fluorescence spectra were recorded on a Fluorolog 3 spectrofluorometer. All measurements were carried out in conven tional quartz cells of $10 \mathrm{~mm}$ pathlength at $20^{\circ} \mathrm{C}$. Preparation and handling of the solutions were carried out under red light.

Time resolved optical experiments were based on a femtosecond $1 \mathrm{kHz}$ Ti:Sapphire system producing $30 \mathrm{fs}, 0.8 \mathrm{~mJ}$ laser pulses centered at $800 \mathrm{~nm}$ (Femtopower Compact Pro) coupled with an optical para metric generator (Light Conversion Topas C) and frequency mixers to excite samples at the maximum of the steady state absorption band. In the case of the time resolved fluorescence measurements, the fluores cence emitted by a sample in the forward direction was collected by reflective optics and focused with a spherical mirror onto the input slit of a spectrograph (Chromex 250) coupled to a streak camera (Hamamatsu 5680) equipped with a fast single sweep unit M5676, temporal resolution $2 \mathrm{ps}$. The convolution of a rectangular streak camera slit in the sweep range of 250 ps with an electronic jitter of the streak camera trigger pulse provided a Gaussian (over 4 decades) temporal apparatus function with a FWHM of 20 ps (for more details see ESI, Section 4.1). For the TRABS experiments, white light con tinuum $(360 \mathrm{~nm} 1000 \mathrm{~nm})$ pulses generated in a $2 \mathrm{~mm} \mathrm{D}_{2} \mathrm{O}$ cell were used as the probe. The variable delay time between excitation and probe pulses was obtained using a delay line with 0.66 fs resolution. The solutions were placed in a $2 \mathrm{~mm}$ circulating cell. White light signal and reference spectra were recorded using a two channel fibre spec trometer (Avantes Avaspec 2048 2). A home written acquisition and experiment control program in LabVIEW made it possible to record transient spectra with an average error less than $10^{-3}$ of optical density for all wavelengths. The temporal resolution of the set up was better than 50 fs (for more details see ESI, Section 4.2).

\section{Note}

Authors declare no competing financial interests.

\section{Acknowledgements}

This work was supported by RFBR (project 1503 04705) and the Russian Science Foundation (project 1613 10226). The publication was financially supported by the Ministry of Education and Science of the Russian Federation (the Agreement number 02.a03.0008). We thank Prof. Dr. Heiko Ihmels (Universität Siegen, Germany) for his kind assistance with the preparation of the manuscript. 
[1] Hader DP, Tevini M. General photobiology. Oxford: Pergamon; 1987.

[2] Kundu S, Patra A. Chem Rev 2017;117:712.

[3] Fan J, Hu M, Zhan P, Peng X. Chem Soc Rev 2013;42:29.

[4] Hedley GJ, Ruseckas A, Samuel IDW. Chem Rev 2017;117:796.

[5] Hildebrandt N, Spillmann CM, Russ Algar W, Pons T, Stewart MH, Oh E, et al. Chem Rev 2017;117:536.

[6] Rowland CE, Delehanty JB, Dwyer CL, Medintz IL. Mater Today 2017;20:131.

[7] Sato S, Murakoshi K, Ikeda K. Chem Lett 2016;45:125.

[8] Haider JM, Williams RM, De Cola L, Pikramenou Z. Angew Chem Int Ed 2003;42:1830.

[9] Cárdenas DJ, Collin J-P, Gaviña P, Sauvage J-P, De Cian A, Fischer J, et al. J Am Chem Soc 1999;121:5481.

[10] Armaroli N, Eckert J-F, Nierengarten J-F. Chem Commun 2000:2105.

[11] Armaroli N, Accorsia G, Rioa Y, Nierengarten J-F, Eckert J-F, Gómez-Escalonilla MJ, et al. Synth Metals 2004:147:19.

[12] Puntoriero F, Nastasi F, Campagna S, Bura T, Ziessel R. Chem Eur J 2010;16:8832

[13] Erbas-Cakmak S, Bozdemir OA, Cakmak Y, Akkaya EU. Chem Sci 2013;4:858.

[14] Indelli MT, Ghirotti M, Prodi A, Chiorboli C, Scandola F, McClenaghan ND, et al. Inorg Chem 2003;42:5489.

[15] Serroni S, Campagna S, Pistone Nascone R, Hanan GS, Davidson GJE, Lehn J-M.

[16] Ward MD, Barigelletti F. Coord Chem Rev 2001;216-217:127.

[17] Denti G, Serroni S, Campagna S, Ricevuto V, Balzani V. Coord Chem Rev 1991;111:227.

[18] Tulyakova EV, Fedorova OA, Fedorov Yu V, Jonusauskas G, Anisimov AV. Russ. Chem. Bull. Int. Ed 2007;56:2166..
[19] Tulyakova EV, Fedorova OA, Fedorov YV, Jonusauskas G, Anisimov AV. J Phys Org Chem 2008;21:372.

[20] Izatt RM, Terry RE, Nelson DP, Chan Y, Eatough DJ, Bradshaw JS, et al. J Am Chem Soc 1976;98:7626.

[21] For example, see Aragoni MC, Arca M, Bencini A, Blake AJ, Caltagirone C, Decortes A, et al. Dalton Trans 2005:2994.

[22] Tulyakova E, Delbaere S, Fedorov Y, Jonusauskas G, Moiseeva A, Fedorova O. Chem Eur J 2011;17:10752.

[23] Berdnikova DV, Fedorov YV, Fedorova OA. Dyes Pigments 2013;96:287.

[24] Van Der Meer BW, Coker G, Chen SYS. Resonance energy transfer: theory and data. New York: VCH; 1994.

[25] Lakowicz JR. Principles of fluorescent spectroscopy. New York: Springer science + Business Media, LLC, Plenum Publishers; 2006.

[26] (a) Grabowski ZR, Rotkiewicz K, Rettig W. Chem Rev 2003;103:3899; (b) Strehmel B, Seifert H, Rettig W. J Phys Chem B 1997;101:2232.

[27] Marmois E. Étude photophysique de nouveaux systemes moleculaires fonctionnels bases sur les styrylpyridines L'Universite Bordeaux 1; 2008. Ph.D. dissertation.

[28] Shida T, Nosaka Y, Kato T. J Phys Chem 1978;82:695.

[29] O'Neill P, Steenken S, Schulte-Frohlinde D. J Phys Chem 1975;79:2773.

[30] (a) Behera GB, Behera PK, Mishra BK. J Surface Sci Technol 2007;23:1 (b) Deligeorgiev T, Vasilev A, Kaloyanova S, Vaquero JJ. Color Technol 2010;126:55.

[31] (a) McRae EG, Kasha M. Augenstein L, Mason R, Rosenberg B, editors. Physical processes in radiation biology. New York: Academic; 1964. p. 23-42; (b) Scherer POJ. Kobayashi T, editor. J-Aggregates. Singapore: World Scientific: 1996. p. 95-110. 